\title{
Assessing the Cultures of Medical Group Practices
}

\author{
Ann Curoe, MD, MPH, John Kralewski, PhD, and Amer Kaissi, MPH
}

Background: The culture of medical group practices is gaining increasing attention as one of the most important organizational factors influencing the costs and quality of health care. Based on organizational theory, we propose that the culture of the practice differs depending on size, ownership, location, and the number of medical specialties.

Methods: A survey was sent to 1223 physicians in 191 clinics in the upper Midwest. The clinic response rate was $77 \%$. The survey instrument identifies 9 culture dimensions, each with 3 to 6 measurement statements.

Results: Smaller clinics had higher scores on 6 of the 9 dimensions. Physician-owned clinics had higher scores on 4 of the 9 dimensions, whereas system-owned clinics had a higher score on only 1 dimension. Only 1 dimension differed among the locations. Single-specialty clinics had higher scores on 4 dimensions and multispecialty clinics had higher scores on 2 dimensions.

Conclusion: Our data confirm the contention that the culture of medical group practices varies considerably; to a degree, this variance is as predicted by organizational theory. The culture changes as group practices become larger and more complex through diversification into multispecialty practices or become part of larger health care systems. (J Am Board Fam Pract 2003;16:394-8.)

The culture of medical group practices is gaining increasing attention as one of the most important organizational factors influencing the costs and quality of health care. Several researchers have found that various dimensions of the practice culture influence the use of care management programs and the costs of care. ${ }^{1,2}$ Quality of care is also being linked to practice cultures. In response to the Institute of Medicine (IOM) report on patient safety, ${ }^{3}$ a subsequent report noted that the culture of medical practices is a fundamental factor that must be addressed to improve the quality of care by reducing adverse events. ${ }^{4}$

Although much has been written about the culture of medical practices, and medical group practices in particular, little empirical research has been devoted to this important area. This article reports the findings from a project designed to further our knowledge of group practice cultures by assessing differences in those cultures in various practice forms. The group practice forms investigated are based on organizational theory (ie, theories about

Submitted, revised, 2 August 2002.

From the Division of Health Services Research and Policy, University of Minnesota School of Public Health, Minneapolis (AC, JK, AK), and the Mayo Clinic, Rochester, Minnesota (AC). Address correspondence to Ann Curoe, MD, MPH, 10835 38th Place North, Plymouth, MN 55411.

This work was supported by Agency for Healthcare Research and Quality. how organizations function). This literature suggests that organizational size and complexity influences both the structure of the organization and how it functions. ${ }^{5}$ Both can be expected to influence the organizational culture. Contingency theory proposes that to be effective, organizations must fit their structures to contingency factors such as strategy, size, task uncertainty, and technology. ${ }^{5}$ Size is how much work is done (ie, the scale on which the work is conducted). ${ }^{6}$ The optimal structure of a small-sized organization is more informal, and decision-making authority is often shared among the participants; that of a large organization, on the other hand, is decentralized but more formal, and although decision-making authority is dispersed to lower levels of the hierarchy, strict rules and regulations guide behavior. Although few empirical studies have been conducted to explore the relationship of size to culture in general, ${ }^{7}$ and none have ben conducted in the health care field, studies have shown that large organizations tend to be more stable, predictable, and disciplined, whereas small organizations are more flexible and tend to have more direct contact with their products and consumers. ${ }^{8}$ This suggests that size is an important variable influencing organizational culture.

Complexity refers to the number of different elements that must be addressed simultaneously in an organization, such as variety of inputs or multi- 
plicity of outputs. For example, if the medical group treats patients with many different diagnoses (inputs), the complexity the group faces is high. The greater the complexity of the inputs, the greater the structural complexity or differentiation needed to accommodate and address the inputs. Scott ${ }^{6}$ defines structure as the "patterned or regularized aspects of the relationship among participants in the organization" (ie, the recurrent patterns of routine interaction and behavior). Complexity or differentiation is often measured as the number of occupational categories and the levels of hierarchy or spatial dispersion. Structural complexity in the group practice, for example, can be measured by the number of different medical specialties present. Similarly, being part of a hospital or a large health plan results in a greater number of hierarchical levels and multiple practice locations, thus resulting in higher structural complexity and differentiation. Structural complexity influences organizational culture, because physicians of different specialties bring diverse values; being part of a system brings a different set of demands from patients, the system itself, and the environment.

Based on these theories, we proposed that (1) large group practice cultures differ from small practice cultures, (2) multispecialty practice cultures differ from single-specialty practice cultures, and (3) physician-owned practices have different cultures than hospital- or health plan-owned practices. The first of these comparisons relates to organizational size; the last 2 are based on organization complexity theory. We explored an additional comparison based on the literature that suggests that rural medical group practices function differently than their urban counterparts. ${ }^{9}$

\section{Methods}

Group practices in Minnesota, North Dakota, South Dakota, and Wisconsin providing services for Blue Cross Blue Shield of Minnesota enrollees were identified and surveyed by mail. The survey instrument "Assessing the Culture of Medical Group Practices" was developed by author JK and his colleagues at the University of Minnesota School of Public Health ${ }^{10}$ and has been reported in an unpublished manuscript. After several iterations, this survey instrument now has 9 dimensions that have been found to explain $74.3 \%$ of the variance in
Table 1. Description of Clinics Included in Study

\begin{tabular}{lrc}
\hline \multicolumn{2}{c}{$\begin{array}{c}\text { Clinics Included in the Survey } \\
(\mathrm{n}=191)\end{array}$} & $\begin{array}{c}\text { Clinics Included } \\
\text { in the Analysis } \\
(\mathrm{n}=148)\end{array}$ \\
\hline Clinic Characteristics & $\begin{array}{c}\text { Number of } \\
\text { Clinics }\end{array}$ & $80(69 \%)^{* *}$ \\
\hline $3-10$ physicians & $116(60 \%)^{*}$ & $38(86 \%)$ \\
$11-20$ physicians & $44(23 \%)$ & $30(97 \%)$ \\
$>21$ physicians & $31(16 \%)$ & $60(87 \%)$ \\
Rural & $69(36 \%)$ & $88(72 \%)$ \\
Urban & $122(64 \%)$ & $63(72 \%)$ \\
Single specialty & $87(46 \%)$ & $85(82 \%)$ \\
Multispecialty & $104(54 \%)$ & $45(85 \%)$ \\
Physician-owned & $53(28 \%)$ & $103(75 \%)$ \\
System-owned & $138(72 \%)$ & \\
\hline
\end{tabular}

*Percentage of total number of clinics.

${ }^{* *}$ Clinic return rate based on clinic characteristics.

group practice cultures. Three to 6 measurement statements support each dimension. The 9 dimensions are: collegiality; information emphasis; quality emphasis; organizational identity; cohesiveness; business emphasis; organizational trust; innovativeness; and autonomy.

The survey was sent to physicians certified in Obstetrics and Gynecology, Pediatrics, Family Practice, or Internal Medicine specialties. For any single clinic, a maximum of 5 physicians within each of these specialties received surveys. Clinics that had fewer than 3 physicians were excluded. The number of physicians per clinic that received a survey ranged from 3 to 20 . For clinics with multiple clinic sites, each site was viewed as an individual clinic.

The survey was sent to a total of 1223 physicians in 191 clinics. The clinics were classified based on number of physicians, location, specialty, and ownership. Based on past research, we placed the clinics in 3 size categories: 3 to 10 physicians, 11 to 20 physicians, and $>21$ physicians. The locations were either urban or rural, with urban defined as the 7-county area surrounding St. Paul/Minneapolis and the cities of Duluth, Rochester, LaCrosse, Fargo/Moorhead, and Sioux Falls (South Dakota). Ownership was defined as the clinic either being physician-owned or part of a group practice or hospital system. Table 1 describes the 191 clinics that were included in the survey and the number of responses. Only clinics from which 2 or more physicians returned the survey were included in the analysis. 
Surveys from physicians at 136 clinics were returned after 1 mailing. A second mailing was sent to the 35 clinics from which only 1 physician returned the survey. Between the 2 mailings, 148 clinics had 2 or more physicians who returned the surveys, for a clinic response rate of $77 \%$. A total of 547 physicians returned the survey. These responses represented all the primary care physicians in some clinics and a range of $25 \%$ to $50 \%$ of those in the other clinics. Twenty-three clinics did not respond, and 20 clinics were excluded because only 1 physician returned the survey. To check for response bias, we compared the respondents with the nonrespondents using our 4 organizational categories. The clinics that were excluded because of $\leq 1$ responses were significantly different from the responding clinics in terms of clinic size and clinic ownership. There was a greater response rate from clinics with $>21$ physicians in the group and from physician-owned clinics. The nonresponding and responding clinics were not significantly different regarding specialty or urban/rural location.

Data from the surveys were summed to create a mean score for each of the 9 cultural dimensions for each clinic. To do this, the mean score for each dimension was calculated for each respondent in each clinic and then the mean of that mean was used for the clinic score. Data were analyzed using one-way analysis of variance. Table 2 shows the mean scores, standard deviations, and statistical significance for the groups.

\section{Results}

Several important findings emerged from our analysis of these data. As expected, as the size of the group practice increases the culture is less collegial, less cohesive (less internal agreement on how to do things), and there is less organizational trust. System clinics also had less organizational trust, less identification with the group practice as an organization, and less collegiality among the physicians, all of which probably flows from the blurring of relationships in clinics that are owned by hospitals or health plans. Unexpectedly, however, the quality emphasis decreases as these organizations increase in size. This is surprising, because with greater size, there is more organizational capacity to focus attention on quality of care and to assure quality performance. As expected, quality emphasis increases as ownership shifts to systems and their larger organizational capacity.

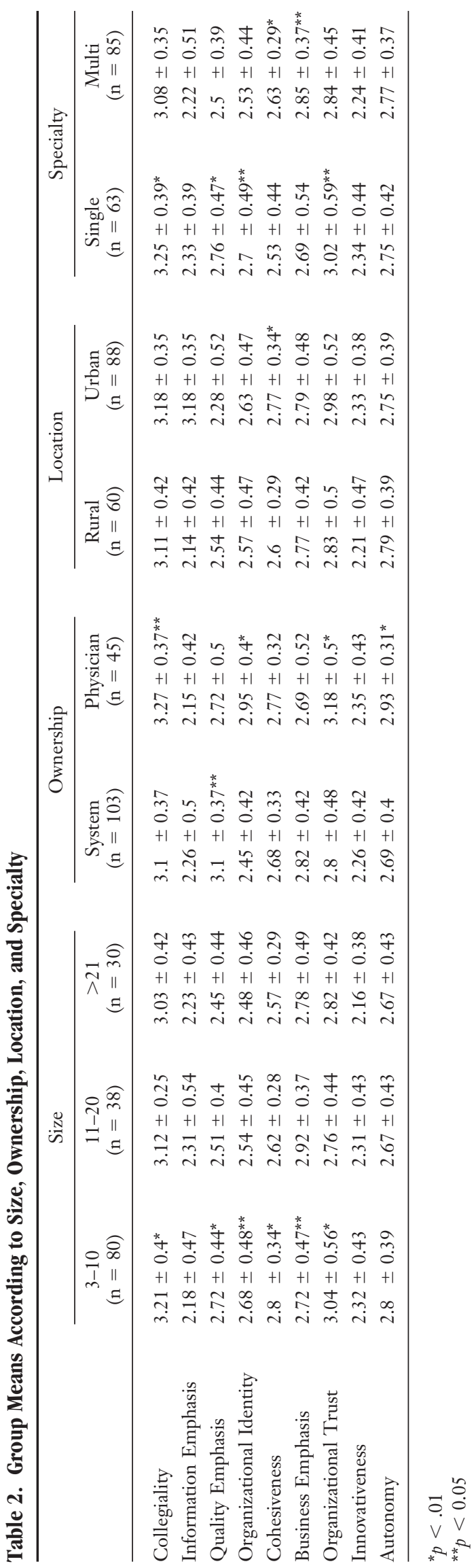


The most pronounced cultural differences were found to be between single and multispecialty group practices. Multispecialty groups have cultures that are less collegial (sense of belonging), have less organizational identity, are less cohesive, and have less organizational trust. Their cultures are also less oriented toward quality of care. It seems that the addition of specialties greatly changes the practice culture and that those changes diminish physicians' orientation toward their colleagues and the practice as a "group practice." However, this does not seem to be the case when single-specialty clinics alone are analyzed. Family practice, pediatric, and internal medicine clinics have similar cultures that do not differ at the .05 level of statistical significance. (Surveys were not sent to clinics with the single specialty of Obstetrics and Gynecology.) These findings are summarized in Table 3.

\section{Discussion}

Our data confirm the contention that the culture of medical group practices varies considerably; to a degree, this variance is as predicted by organizational theory. The culture changes as group practices become larger and more complex through diversification into multispecialty practices or become part of larger health care systems. However, some dimensions of the practice culture seem to be more sensitive to these different venues than others. The dimensions related to quality of care and organizational trust are particularly noteworthy in this regard; quality is influenced by all 4 of the organizational forms included in this study, and trust is influenced by 3 of the four. Cohesiveness and organizational identity are also quite sensitive to these different organizational forms and in the direction that would be predicted by organizational theory. On the other hand, the information, business emphasis, innovativeness, and autonomy cultural dimensions do not seem to be very sensitive to these different organizational environments. In some cases, the lack of variance between different organizational forms results from the considerable variance within those forms. For example, the business orientation, innovativeness, and information emphasis cultural dimensions vary a great deal within the various organizational forms, indicating that there are important cultural differences among the group practices within each practice form (ie,

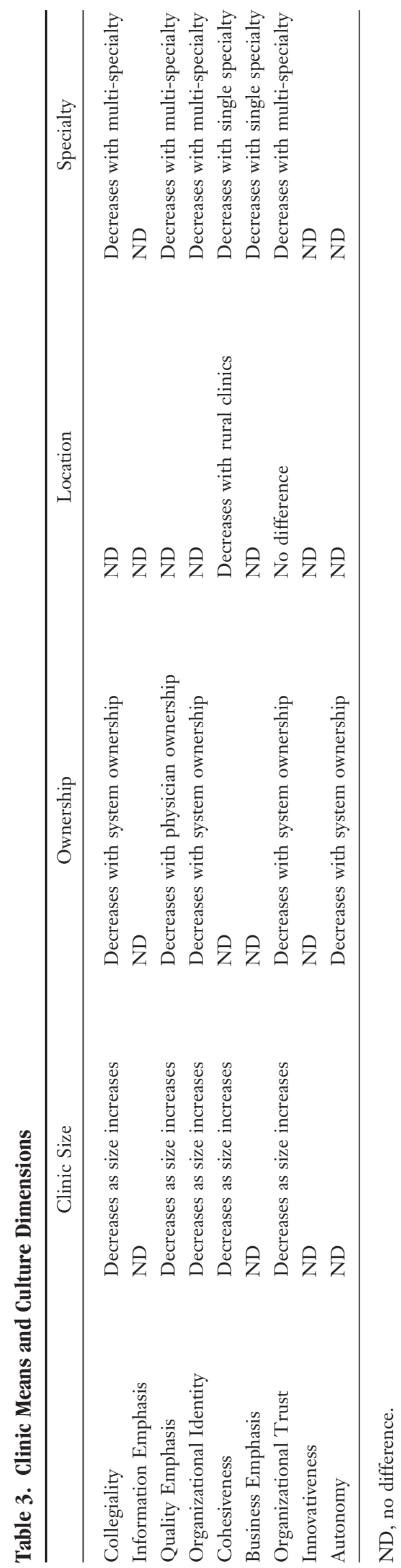


group size, urban location, etc). This finding is as important as the findings of variances between organizational forms. For example, the variance in some cultural dimensions among group practices within size categories may be the cause of the conflicting findings regarding the effects of practice size on performance. ${ }^{11}$ This same phenomenon might also account for the few differences found between urban and rural practices, although the rural practices exhibit a distinct cultural pattern that does not mirror any of the other organizational forms (ie, less emphasis on information systems, less emphasis on innovativeness, but organizational trust similar to that of urban practices).

Our study demonstrates that the culture of medical group practices varies both between and within organizational forms. It also demonstrates that the culture survey instrument used in this study can be a useful tool in assessing group practice cultures and managing those cultures effectively. Our study also points the way for further research focused on the culture of group practices. If we are to be successful in establishing cultures that improve the quality of care and encourage clinicians to use resources effectively and efficiently, we must learn more about the relationships of the cultural dimensions identified in this research and practice characteristics. This should be the agenda for future research in the area. In the meantime, group practice physicians should be aware of the fact that practice cultures vary and that those cultures have an influence on the cost and quality of their patient care.

\section{References}

1. Shortell SM, Jones RH, Rademaker AW, et al. Assessing the impact of total quality management and organizational culture on multiple outcomes of care for coronary artery bypass graft surgery patients. Med Care 2000;38(2):207-17.

2. Kralewski JE, Rich EC, Feldman R, et al. The effects of medical group practice and physician payment methods on cost of care. Health Serv Res 2000;35: 591-613.

3. Kohn LT, Corrigan JM, Donaldson MS, editors. To err is human: building a safer health system. Committee on Quality of Health Care in America, Institute of Medicine. Washington, DC: National Academy Press, 2000. Available at: URL: http://www. nap.edu/books/0309068371/html/

4. Committee on Quality of Health Care in America. Crossing the quality chasm: a new health system for the 21st Century. Institute of Medicine. Washington, DC: National Academy Press, 2001. Available at: URL: http://www.nap.edu/books/0309072808/ html/

5. Donaldson L. The normal science of structural contingency theory. In: Clegg SR, Hardy C, Nord WR, editors. Handbook of organization studies. Thousand Oaks, CA: Sage Publishing, 1996:57-76

6. Scott WR. Organizations. Rational, natural and open systems. 4th ed. Upper Saddle River, NJ: Prentice Hall, 1998.

7. Pratt J, Beaulieu P. Organizational culture in public accounting: size, technology, rank and functional area. Accounting, Organizations and Society 1992; 17:667-84.

8. Bennis W. Large vs small. Executive Excellence 1993;10(6):3-6.

9. Kralewski JE, Rich EC, Bernhardt T, Dowd BE, Feldman R, Johnson C. The organizational structure of medical group practices in a managed care environment. Health Care Manag Review 1998;23: 76-93.

10. Kralewski JE, Wingert T, Barbouche MH. Assessing the culture of medical group practices. Med Care 1996;34:377-88.

11. Robinson JC. Theory and practice in the design of physician payment incentives. Millbank Q 2001;79: 149-77. 